\title{
Robust Estimation of Marginal Abatement Cost of Water Pollutant: Evidence from Yangtze River Basin
}

\author{
Wang Kai ${ }^{1, a}$, Zhang Hengquan ${ }^{1}$ \\ ${ }^{1}$ Bussiness School, Hohai University, 211100 Nanjing, P.R. China
}

\begin{abstract}
Based on the econometric method of bootstrap for 1000 times, this study estimated the marginal abatement cost of water pollutant, $\mathrm{COD}$ and $\mathrm{NH}_{3}-\mathrm{N}$, for 9 provinces and 2 municipalities in the Yangtze River Basin from 2001 to 2017 by building a robust estimation model. We found that the marginal abatement cost increases at an average annual rate of $19.47 \%$. The marginal abatement cost in Jiangsu and Sichuan are significantly higher than other regions. Differences in marginal abatement cost make it possible to trade emission rights between regions.
\end{abstract}

\section{Introduction}

The measurement of the marginal abatement cost (MAC) of water pollutants is essential for judging the economic cost, pressure and potential of reducing water pollutants. The theoretical basis of the MAC is the duality in the theory of environmental production technology. The essence of MAC is the marginal conversion rate of good output to bad output.

Generally, when the value of the good output lost to reduce one unit of pollutant emissions is greater, the price of unit pollutant emission right will be higher. Otherwise, rational manufacturers lack sufficient incentives to participate in selling the emissions rights. However, if the emission rights trading market is absent, the historical price of emission rights is naturally missing. The MAC, an opportunity cost to reduce pollutant emissions, is regarded as the shadow price of pollutants, which can reference the formation of the initial price of emissions rights trading. Thus, measuring the MAC of water pollutants can provide policy decision for improving market-based and pricebased water related environmental regulations.

The Yangtze River Basin is one of the most critical economic and industrial water pollutants discharge concentrated areas in China. From 2001 to 2017, the average annual industrial production value of the nine provinces and two municipalities through which the Yangtze River flows reached 3.090 billion CNY, accounting for $28.11 \%$ of the country, and industrial wastewater discharge accounted for $47.47 \%$ of the total emissions. The industrial wastewater discharge in the provinces (municipalities) in the Yangtze River Basin is still under tremendous pressure. Obviously, the COD and $\mathrm{NH}_{3}-\mathrm{N}$ of industrial water pollutants are the focus of environmental control. The "14 ${ }^{\text {th }}$ Five-Year Plan" proposes to reduce $\mathrm{COD}$ and $\mathrm{NH}_{3}-\mathrm{N}$ emissions by $8.0 \%$, respectively. However, the study on the MAC of industrial

\footnotetext{
a Corresponding author: wangkai_hhubs@hhu.edu.cn
}

water pollutants is limited.

This study aims to answer the following 2 questions: (1) What is the MAC of COD and $\mathrm{NH}_{3}-\mathrm{N}$ in 9 provinces and 2 municipalities along the Yangtze River Basin? (2) What is the temporal evolution and spatial distribution of the MAC of water pollutants? The remainder of this study is organized in the following manner. Section 2 introduces the model and presents the empirical specification. Section 3 presents the data, variables and reports the main results. Section 4 presents a further discussion and summarizes this study.

\section{Method}

We use a framework of environmental production technology and the directional distance function (DDF) to model the efficiency assessment to estimate the MAC of pollutants.

Denote inputs by $x=\left(x_{1}, \ldots, x_{N}\right) \in \mathbf{R}_{+}^{N}$, good outputs by $y=\left(y_{1}, \ldots, y_{M}\right) \in \mathbf{R}_{+}^{M}$, and bad outputs by $b=\left(b_{1}, \ldots, b_{J}\right) \in \mathbf{R}_{+}^{J}$. The technology is represented by the output sets $P(x), x \in \mathbf{R}_{+}^{N}$ as

$$
P(x)=\{(y, b): x \text { can produce }(y, b)\} .
$$

In the framework of environmental production technology, the inputs and good outputs are assumed to be freely disposable while the good and bad outputs are jointly weakly disposable. While no good output can be produced without bad output, which is referred to as the null-jointness assumption. The DDF can be described as follows:

$$
\vec{D}_{o}(x, y, b ; g)=\max \left\{\beta:\left(y+\beta g_{y}, b-\beta g_{b}\right) \in P(x)\right\}
$$

where $\left(g_{y},-g_{b}\right) \in \mathbf{R}_{+}^{M} \times \mathbf{R}_{+}^{J}$ is the directional vector, and $\beta$ is the value of DDF which means the maximum expansion of good outputs and contraction of bad outputs. 
Following the research of Färe and Grosskopf ${ }^{[1]}$, the directional vector is set as $\left(g_{y},-g_{b}\right)=(1,-1)$. The Parametric quadratic specification of DDF can be formulated as follows:

$$
\begin{aligned}
\vec{D}_{o}^{t}=\left(x_{K}^{t}, y_{K}^{t}, b_{K}^{t} ; 1 ;-1\right)= & +\sum_{n=1}^{N} \alpha_{n} x_{n k}^{t}+\sum_{m=1}^{M} \beta_{m} y_{m k}^{t}+\sum_{j=1}^{J} \gamma_{j} b_{j k}^{t} \\
& +\frac{1}{2} \sum_{n=1}^{N} \sum_{n^{\prime}=1}^{N} \alpha_{n n^{\prime}} x_{n k}^{t} x_{n^{\prime} k}^{t} \\
& +\frac{1}{2} \sum_{m=1}^{M} \sum_{m^{\prime}=1}^{M} \beta_{m m^{\prime}} y_{m k}^{t} y_{m^{\prime} k}^{t} \\
& +\frac{1}{2} \sum_{j=1}^{J} \sum_{j^{\prime}=1}^{J} \gamma_{j j^{\prime}} b_{j k}^{t} b_{j^{\prime} k}^{t} \\
& +\sum_{n=1}^{N} \sum_{m=1}^{M} \delta_{n m} x_{n k}^{t} y_{m k}^{t} \\
& +\sum_{n=1}^{N} \sum_{j=1}^{J} \eta_{n j} x_{n k}^{t} b_{j k}^{t}+\sum_{m=1}^{M} \sum_{j=1}^{J} \mu_{m j} y_{m k}^{t} b_{j k}^{t}
\end{aligned}
$$

where $k$ denotes the DMU and $t$ denotes the year. Formula (4) and (5) aim at minimizing the sum of the deviations of the distances subject to the properties of feasibility, nonjointness, monotonicity, translation and symmetry.

$$
\operatorname{minimize} \sum_{t=1}^{T} \sum_{k=1}^{K}\left[\vec{D}_{o}^{t}\left(x_{k}^{t}, y_{k}^{t}, b_{k}^{t} ; 1,-1\right)-0\right]
$$

s.t.

$$
\begin{aligned}
& \vec{D}_{o}^{t}\left(x_{k}^{t}, y_{k}^{t}, b_{k}^{t} ; 1,-1\right) \geq 0 k=1, \ldots, K ; t=1, \ldots, T \\
& a_{n n^{\prime}}=a_{n^{\prime} n}, n \neq n^{\prime} ; \beta_{m m^{\prime}}=\beta_{m^{\prime} m}, m \neq m^{\prime} ; \gamma_{j j^{\prime}}=\gamma_{j^{\prime} j}, j \neq j^{\prime} \\
& \partial \vec{D}_{o}^{t}\left(x_{k}^{t}, y_{k}^{t}, b_{k}^{t} ; 1,-1\right) / \partial y_{m}^{t} \leq 0, m=1, \ldots, M \\
& \partial \vec{D}_{o}^{t}\left(x_{k}^{t}, y_{k}^{t}, b_{k}^{t} ; 1,-1\right) / \partial x_{n}^{t} \geq 0, n=1, \ldots, N \\
& \partial \vec{D}_{o}^{t}\left(x_{k}^{t}, y_{k}^{t}, b_{k}^{t} ; 1,-1\right) / \partial b_{j}^{t} \geq 0, j=1, \ldots, J \\
& \sum_{m=1}^{M} \beta_{m}-\sum_{j=1}^{J} \gamma_{j}=-1
\end{aligned}
$$

Table 1. The Descriptive Statistics of Inputs and Outputs.

$$
\begin{aligned}
& \sum_{m^{\prime}=1}^{M} \beta_{m m^{\prime}}-\sum_{j=1}^{J} \mu_{m j}=0, m=1, \ldots, M \\
& \sum_{m=1}^{M} \mu_{m j}-\sum_{j^{\prime}=1}^{J} \gamma_{j j^{\prime}}=0, j=1, \ldots, J \\
& \sum_{m=1}^{M} \delta_{n m}-\sum_{j=1}^{J} \eta_{n j}=0, n=1, \ldots, N
\end{aligned}
$$

Denotes the parameter vector by using single estimate and bootstrap as $\hat{\theta}, \hat{\theta}_{s}^{*}$, where the $s$ means the times of sampling. For each year we have $k$ DMUs, thus the probability of drawing from the original sample (with reversion sampling) to each observation point is $1 / k^{[2]}$. Based on $\hat{\theta}_{S}^{*}$ and duality, we can calculate the $\operatorname{MAC}\left(q^{*}\right)$ for bootstrap as follows:

$$
q_{j}^{*}=-1 \times \frac{\partial \vec{D}_{T}\left(x^{*}, y^{*}, b^{*} ; g_{y},-g_{b}\right) / \partial b_{j}^{*}}{\partial \vec{D}_{T}\left(x^{*}, y^{*}, b^{*} ; g_{y},-g_{b}\right) / \partial y_{m}^{*}}
$$

\section{Data and results}

\subsection{Data source}

The input factors include capital $\left(x_{1}\right)$, labor $\left(x_{2}\right)$, and industrial water consumption $\left(x_{3}\right)$, the good output is the industrial production value $\left(y_{1}\right)$, and the bad outputs are the COD $\left(b_{1}\right)$ and $\mathrm{NH}_{3}-\mathrm{N}\left(b_{2}\right)$ emissions. 11 decisionmaking units (DMUs) are 9 provinces and 2 municipalities including Shanghai (SH), Jiangsu (JS), Zhejiang (ZJ), Anhui (AH), Jiangxi (JX), Hubei (HB), Hunan (HN), Chongqing (CQ), Sichuan (SC), Yunnan (YN) and Qinghai (QH). The inputs and good output data are collected from China Statistical Yearbook (2001-2017). The bad outputs data are collected from the China Water Resources Bulletin and China Environment Yearbook (2001-2017).

\begin{tabular}{llrrrrr}
\hline \multicolumn{1}{c}{ Variables } & Units & Mean & S.D. & Min & Max & Median \\
\hline Captial $\left(x_{1}\right)$ & $10^{8} \mathrm{CNY}$ & 5602.58 & 5446.78 & 395.99 & 32286.51 & 4024.05 \\
Labor $\left(x_{2}\right)$ & $10^{4}$ Person & 286.66 & 267.98 & 9.90 & 1153.88 & 208.44 \\
Water $\left(x_{3}\right)$ & $10^{8} \mathrm{~m}^{3}$ & 69.70 & 49.86 & 2.40 & 239.00 & 60.7 \\
Industrial production value $(y)$ & $10^{8} \mathrm{CNY}$ & 20597.28 & 26107.53 & 181.39 & 147308.90 & 11553.31 \\
Industrial COD emission $\left(b_{1}\right)$ & Ton & 149159.10 & 98484.29 & 2927.40 & 529052.90 & 125811 \\
Industrial $\mathrm{NH}_{3}-\mathrm{N}$ emission $\left(b_{2}\right)$ & Ton & 12977.70 & 10630.27 & 12.20 & 50504.70 & 11004.9 \\
\hline
\end{tabular}

\subsection{Parameter estimation}

Based on bootstrap for 1000 times, the parameters of single estimate and bootstrap revision for the quadratic form of the DDF are provided in Table 2.

Table 2. The Parameter Estimates.

\begin{tabular}{rrcc}
\hline Variables & Original & S.E. & Revision \\
\hline $\mathrm{a}_{0}$ & $-6.59 \mathrm{E}+04$ & $2.41 \mathrm{E}+04$ & $-7.73 \mathrm{E}+04$ \\
\hline
\end{tabular}

\begin{tabular}{llrrr}
\hline & $\mathrm{a}_{1}$ & $4.04 \mathrm{E}-03$ & $7.88 \mathrm{E}-04$ & $9.59 \mathrm{E}-04$ \\
$a_{\mathrm{n}}$ & $\mathrm{a}_{2}$ & $1.36 \mathrm{E}-03$ & $8.40 \mathrm{E}-04$ & $1.09 \mathrm{E}-03$ \\
& $\mathrm{a}_{3}$ & $1.27 \mathrm{E}+02$ & $2.01 \mathrm{E}+02$ & $2.46 \mathrm{E}+02$ \\
$\beta_{\mathrm{m}}$ & $\beta_{1}$ & $-5.86 \mathrm{E}-04$ & $2.06 \mathrm{E}-04$ & $-1.25 \mathrm{E}-04$ \\
& $\gamma_{1}$ & $3.09 \mathrm{E}-01$ & $1.60 \mathrm{E}-01$ & $2.36 \mathrm{E}-01$ \\
& $\gamma_{2}$ & $6.91 \mathrm{E}-01$ & $1.60 \mathrm{E}-01$ & $7.64 \mathrm{E}-01$ \\
& $\mathrm{a}_{11}$ & $5.86 \mathrm{E}-11$ & $8.70 \mathrm{E}-12$ & $-8.63 \mathrm{E}-12$ \\
$a_{\mathrm{nn}}$ & $\mathrm{a}_{12}$ & $1.61 \mathrm{E}-11$ & $3.62 \mathrm{E}-12$ & $-2.52 \mathrm{E}-12$ \\
& $\mathrm{a}_{13}$ & $5.73 \mathrm{E}-06$ & $9.82 \mathrm{E}-07$ & $-6.71 \mathrm{E}-07$ \\
\hline
\end{tabular}




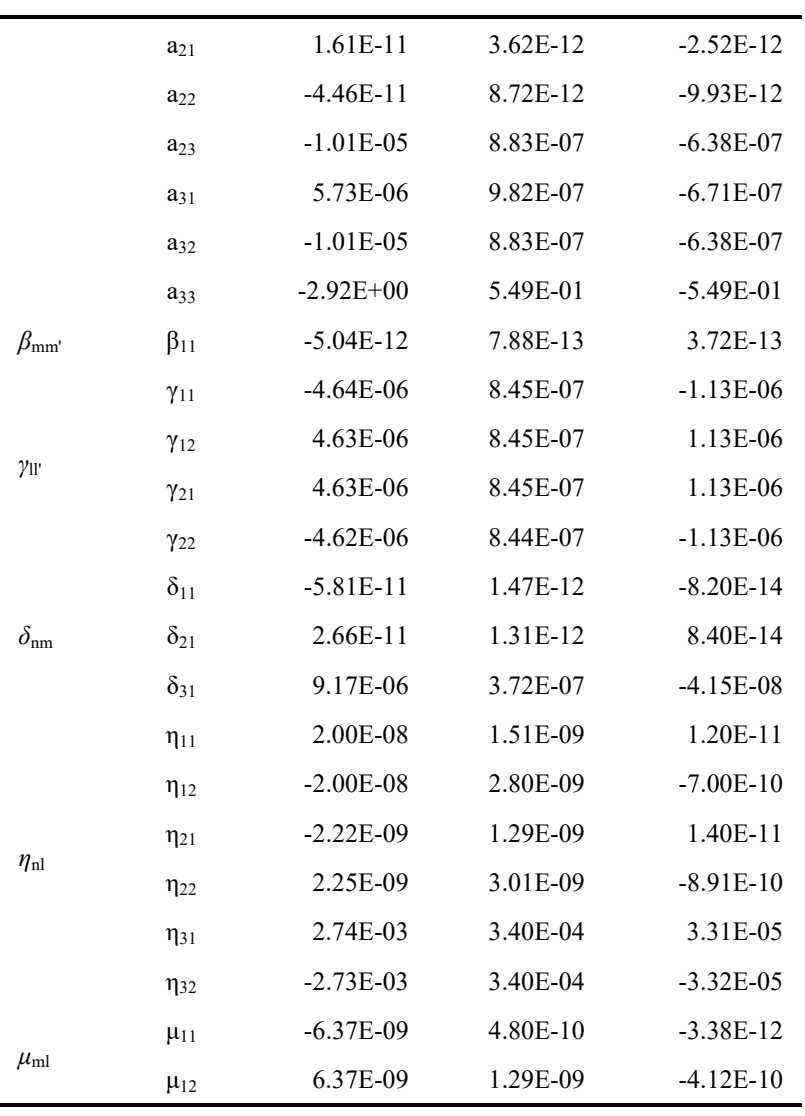

\subsection{Spatiotemporal differences in MAC}

\subsubsection{Analysis of time difference in MAC}

Substituting the parameters revised by bootstrap into the formula 5, can estimate the MAC of $\mathrm{COD}$ and $\mathrm{NH}_{3}-\mathrm{N}$. Table 3 reports the estimation on the MAC of 11 DMUs from 2001 to 2017. Generally, the MACs have increased year by year by an average annual increase of $11.33 \%$. In particular, the MACs of $\mathrm{NH}_{3}-\mathrm{N}$ with an average annual increase of $19.47 \%$. However, the changing trend of the MACs of COD is more diverse. First, Jiangsu has shown a gradual decline, from $842,400 \mathrm{CNY} / \mathrm{Ton}$ in 2001 to $328,700 \mathrm{CNY} /$ Ton in 2017 by a decline of $60.98 \%$.

Table 3. The Estimates of MAC by Bootstrap.

\begin{tabular}{|c|c|c|c|c|}
\hline & & Mean & 2001-2010 & 2011-2017 \\
\hline \multirow{11}{*}{ 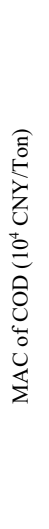 } & SH & 192.79 & 198.98 & 185.67 \\
\hline & JS & 80.50 & 73.01 & 107.81 \\
\hline & ZJ & 103.42 & 104.78 & 102.60 \\
\hline & $\mathrm{AH}$ & 154.16 & 158.05 & 147.34 \\
\hline & JX & 119.81 & 119.92 & 122.90 \\
\hline & $\mathrm{HB}$ & 166.47 & 164.91 & 162.25 \\
\hline & $\mathrm{HN}$ & 106.97 & 109.13 & 97.71 \\
\hline & CQ & 142.15 & 148.36 & 125.35 \\
\hline & $\mathrm{SC}$ & 173.42 & 204.98 & 80.95 \\
\hline & YN & 150.15 & 156.40 & 138.82 \\
\hline & QH & 150.70 & 153.59 & 143.67 \\
\hline \multirow{11}{*}{ 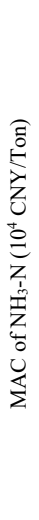 } & $\mathrm{SH}$ & 1257.48 & 1367.16 & 931.61 \\
\hline & JS & 3501.09 & 4320.19 & 1195.28 \\
\hline & ZJ & 1011.99 & 1165.81 & 521.30 \\
\hline & $\mathrm{AH}$ & 560.08 & 665.72 & 219.38 \\
\hline & JX & 263.25 & 307.32 & 148.92 \\
\hline & HB & 812.27 & 909.50 & 463.85 \\
\hline & $\mathrm{HN}$ & 332.77 & 393.80 & 145.78 \\
\hline & CQ & 279.75 & 352.29 & 102.78 \\
\hline & $\mathrm{SC}$ & 1320.01 & 1689.22 & 338.52 \\
\hline & YN & 474.82 & 563.70 & 230.65 \\
\hline & $\mathrm{QH}$ & 188.30 & 210.14 & 127.24 \\
\hline
\end{tabular}
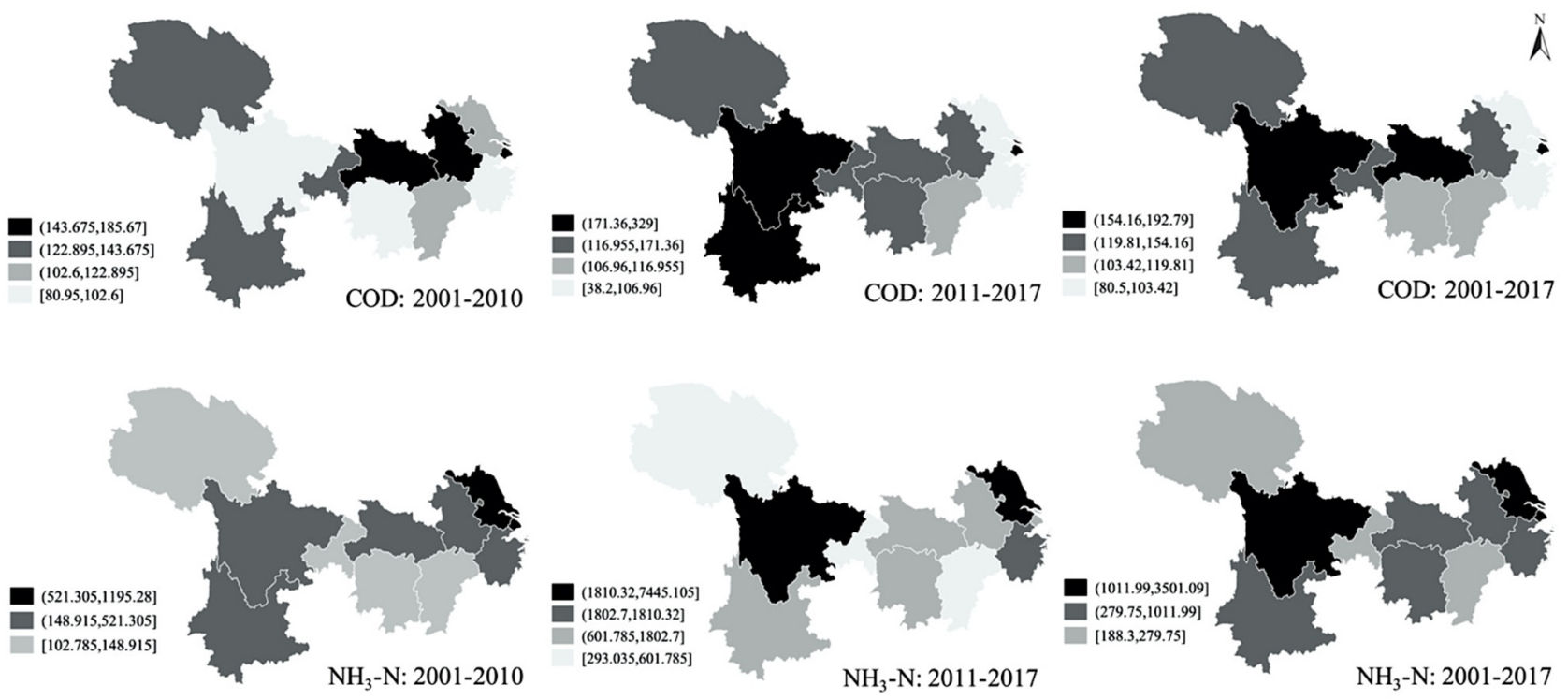

Figure 1. The Spatial Distribution of MAC $\left(10^{4} \mathrm{CNY} / \mathrm{Ton}\right)$.

Secondly, the changing trend of MACs of COD in Jiangxi and Hebei is opposite. The MACs of COD in
Jiangxi decreased first and showed an upward trend in 2016-2017. However, the MACs of COD in Hebei 
increased first and showed a downward trend from 2011 to 2015. Finally, Figure 2 shows the Kernel Density of MACs from 2001 to 2017 . It shows that the density peaks of the MAC of $\mathrm{COD}$ and $\mathrm{NH}_{3}-\mathrm{N}$ move to the right gradually over time, which is consistent with the analysis of the annual trend of MAC in each DMU.

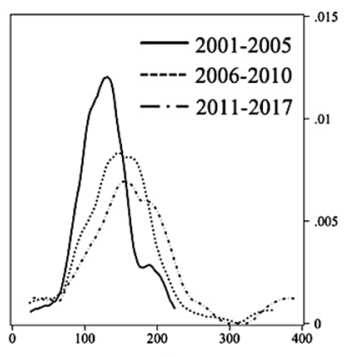

MAC of COD

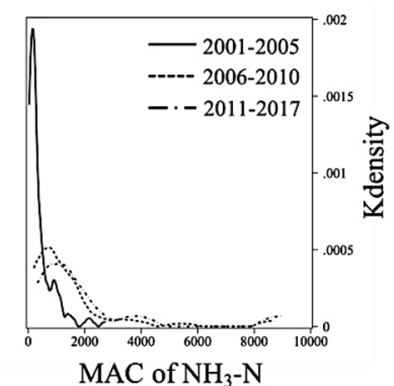

$\mathrm{MAC}$ of $\mathrm{NH}_{3}-\mathrm{N}$
Figure 2. The Kernel Density of MAC.

\subsubsection{Analysis of spatial difference in MAC}

Figure 1 shows the spatial distribution of MACs of COD and $\mathrm{NH}_{3}-\mathrm{N}$ for 9 provinces and 2 municipalities in the Yangtze River Basin. The eastern, central and western provinces all have a higher MAC, such as Shanghai, Hubei and Sichuan. Jiangsu and Sichuan have a higher MAC of $\mathrm{NH}_{3}-\mathrm{N}$. On the contrary, Jiangxi, Hunan, Chongqing and Qinghai in central and western part of China have a relatively low marginal cost of emissions.

Figure 3 shows the extent to which DMU's MAC deviates from the mean level. From 2001 to 2017, the average MAC of COD is 14.05 million CNY/Ton, and the average MAC of $\mathrm{NH}_{3}-\mathrm{N}$ is 9.0925 million $\mathrm{CNY} /$ Ton. The MAC of COD in each DMU deviates from the overall mean by a small amount, while MAC of $\mathrm{NH}_{3}-\mathrm{N}$ deviates significantly as its standard deviation is $1439.72\left(10^{4}\right.$ CNY/Ton). Especially, the MAC of $\mathrm{NH}_{3}-\mathrm{N}$ in Jiangsu, Shanghai, and Sichuan is significantly higher than the overall mean level. DMUs that fell below the overall mean are Qinghai, Yunnan, Chongqing, Hunan, Jiangxi, and Anhui, mainly located in central and western parts of China.

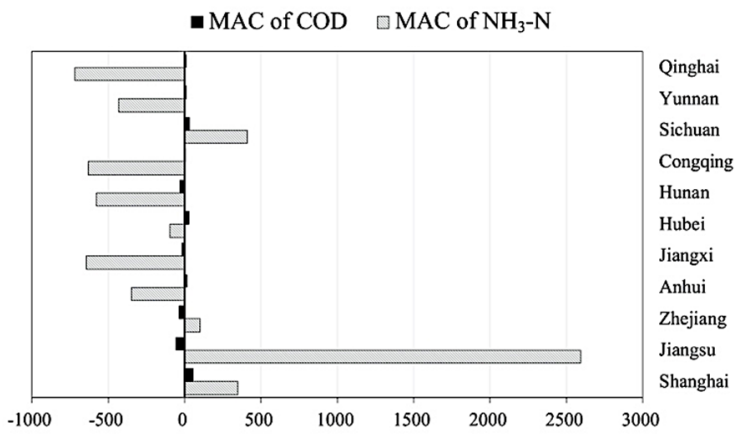

Figure 3. The Deviation from the Mean of MAC $\left(10^{4}\right.$ CNY/Ton).

\subsubsection{Analysis of regional difference in MAC}

We select the Theil index to measure the regional difference and variation range of MAC reduction. Figure 4 shows that the regional differences of MACs of COD and $\mathrm{NH}_{3}-\mathrm{N}$ have increased significantly compared with the beginning of the period. More than $50.00 \%$ of the regional differences come from intra-regional differences, which is also consistent with the results of the spatial characteristics of the MAC. Due to limited space, the reader can contact the author for detailed data.

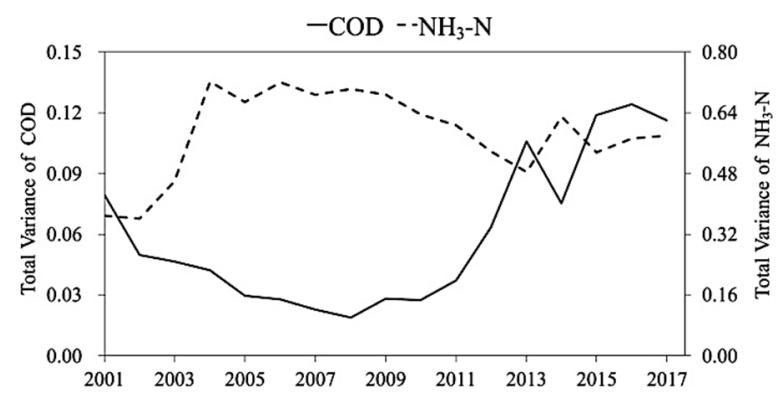

Figure 4. Total Variance of MAC by Theil Index.

\section{Discussion and Conclusion}

Prior work has estimated the MAC by non-parametric data envelopment analysis, parametric stochastic frontier analysis and single estimate under parametric function by DDF. ${ }^{[3,4]}$ However, these studies either fail to deal with the impact of the random effect on parameter estimation or fail to impose constraints on the technical production function, resulting in the deviation of parameter estimation. ${ }^{[5,6]}$

In this study, we use bootstrap 1000 times to obtain the sampling distribution of estimated parameters through random sampling and multiple estimations of model parameters to revise the deviation of a single estimated parameters and obtain a more robust estimate of the MAC.

We found that MAC increased year by year on the whole, while some provinces showed a downward trend. If the output of pollutants is low, it becomes more challenging to take a step forward to reduce pollution emissions, and the value of the economic output forgone to reduce a unit of pollution emissions is high. There is an apparent upward trend in the MAC in Sichuan and Yunnan. Thus, the government can transfer the emission reduction tasks from these provinces to regions with a relatively lower MAC, such as Zhejiang, Jiangxi and Hunan provinces in eastern and central China. Therefore, future work should include follow-up work designed to construct the price formation mechanism of emission rights trading in the Yangtze River basin.

\section{ACKNOWLEDGMENT}

This study was supported by the Fundamental Research Funds for Central Universities [No. 2017B723X14] and Postgraduate Research \& Practice Innovation Program of Jiangsu Province [No. KYCX17_0512].

\section{REFERENCES}

1. R. Färe, S.C. Grosskopf. Theory and Application of Directional Distance Functions. J. Product. Anal. 13, 
93 (2000)

2. J. Weijie., Z. Shaohua. Robust Estimation and Application of Shadow Price of $\mathrm{CO}_{2}$ : Evidence from China. Mgt. Word 34, 32 (2018)

3. R. Färe, S.C. Grosskopf., G. Whittaker. Directional Output Distance Functions: Endogenous Directions Based on Exogenous Normalization Constraints. J. Product. Anal. 40, 267 (2013)

4. R. Färe, C. Pasurka, M. Vardanyan. On Endogenizing Direction Vectors in Parametric Directional Distance Function-based Models. Eur. J. Oper. Res. 262, 361 (2017)

5. T. Zhengge. The Shadow Price of Industrial $\mathrm{SO}_{2}$ Emission: A New Analytic Framework. Cn. Econ. Q. 9, 259 (2010)

6. M. Zanpu. The Non-uniqueness of Shadow Prices in Linear Programming. Systems Engineering 25, 119 (2007) 